\title{
O recurso à modelação no ensino das ciências: um estudo com modelos geológicos
}

\author{
The use of modelling in science teaching: \\ a study with geological models
}

\author{
Cândida Ferreira $^{1}$. Ana Alencoão ${ }^{2}$. Clara Vasconcelos ${ }^{3}$
}

\begin{abstract}
Resumo: Tendo como base as temáticas de geologia do currículo da disciplina de Biologia e Geologia do $11^{\circ}$ ano (amplitude de idades dos 15-17 anos), desenvolveu-se um estudo de investigação recorrendo-se à Aprendizagem Baseada na Resolução de Problemas (ABRP), utilizando-se a modelação como estratégia didática. Pretendendo-se investigar se a modelação potenciava aprendizagens significativas nos alunos, implementou-se um programa de intervenção recorrendo-se a modelos geológicos durante cinco semanas (24 horas letivas). A investigação realizada, apoiada nos moldes de uma Investigação e Desenvolvimento (I\&D), recorreu à triangulação metodológica suportada em várias técnicas e diversos instrumentos de recolha de dados. A modelação permitiu envolver os alunos numa crescente formulação de explicações e de hipóteses e numa maior procura de explicações para responder às questões-problema. Os dados recolhidos permitiram, ainda, concluir quanto ao acréscimo da recolha de evidências num aperfeiçoamento da autonomia e numa melhoria dos resultados escolares.
\end{abstract}

Palavras-chave: Educação em ciências. Ensino de geologia. Modelação análoga. Triangulação metodológica. Modelos geológicos.

\begin{abstract}
Integrating themes of geology that are included in the Biology and Geology curricula of secondary school (students age range 15-17), a Problem-Based Learning (PBL) study was developed using a modeling strategy. With the intention of investigating if modeling could promote meaningful learning in students, an intervention program using geological models was implemented during 5 weeks (24 hours). The Research \& Development promoted was methodologically-based through triangulation and used many techniques and instruments to collect data. Modeling allowed students to be increasingly involved in elaborating explanations and formulating hypothesis, as well as in a broader search for explanations to solve problems. The collected data led to the conclusion that meaningful science learning was performed by students as shown by their increase in searching for evidence, in autonomy, and in a higher school assessment scores.
\end{abstract}

Keywords: Science education. Geology teaching. Modeling. Methodological triangulation. Geologic models.

\footnotetext{
${ }^{1}$ Escola Secundária S/3 S. Pedro. Rua Morgado de Mateus, 5000, Vila Real, Portugal.

E-mail: candidaferreiravrl@sapo.pt

${ }^{2}$ Departamento de Geologia, Universidade de Trás-Os-Montes e Alto Douro, Vila Real, Portugal.

${ }^{3}$ Departamento de Geociências, Ambiente e Ordenamento do Território, Faculdade de Ciências, Universidade do

Porto, Portugal.
} 


\section{Introdução}

Podendo a escola não ser o local onde se inicia a formação científica do aluno é, certamente, o espaço pedagógico privilegiado para a sua consolidação e enriquecimento. Sendo o professor o responsável pela criação de contextos de aprendizagem que possibilitem, aos alunos, aprenderem a aprender, a saberem pensar e a prepararem-se para uma aprendizagem ao longo da vida (LEITE; ESTEVES, 2006), o papel do professor deve acompanhar a rápida evolução do conhecimento científico. Os jovens estudantes, no final do ensino secundário (idade média entre os 17-18 anos), apresentam falta de preparação científica para enfrentarem as dificuldades do Ensino Superior, revelando-se essa escassa literacia quando ingressam no mercado de trabalho (VASCONCELOS; ALMEIDA, 2012). Tal facto resulta, em parte, da existência de conteúdos curriculares e de metodologias pouco interessantes e insuficientemente apelativas para os jovens, não os seduzindo para o prosseguimento de estudos na área das ciências. Osborne e Dillon (2008) relatam que é fraco o interesse dos alunos pelas ciências em contraste com elevados resultados nos testes, encontrando-se, mesmo, uma correlação negativa entre eles. O Projeto ROSE (The Relevance of Science Education), de índole internacional, que realizou uma investigação comparativa com o objetivo de encontrar evidências para melhorar o ensino da ciência e da tecnologia, obteve resultados que confirmam que quanto mais desenvolvido é um país, menor é o número de jovens interessados pela ciência (SJØBERG; SCHREINER, 2005; VASCONCELOS; ALMEIDA, 2012). Estes resultados alertaram as autoridades competentes de ensino, e os docentes em geral, para a necessidade de se reverem os currículos e as práticas letivas, sendo necessário adotar metodologias de ensino que promovam a mobilização de conhecimentos capazes de serem transferidos e aplicados em novas situações.

Tendo como pressuposto o anteriormente referido, com base em temáticas de geologia do currículo da disciplina de Biologia e Geologia do $11^{\circ}$ ano (amplitude média da idade dos alunos de 15-17 anos), desenvolveu-se um estudo de investigação recorrendo à Aprendizagem Baseada na Resolução de Problemas (ABRP) e utilizando a modelação como estratégia didática. Pretendeu-se verificar se era possível integrar a ABRP e a modelação num ensino significativo das ciências, mormente recorrendo a modelos geológicos como defendido nos programas escolares e defendido pela literatura internacional da especialidade. Refira-se que o conceito de geologia usado neste trabalho, e em consonância com o preconizado pelo Ministério da Educação de Portugal para o programa da disciplina envolvida neste estudo, compreende o conceito de geologia no seu sentido mais amplo, devendo ser entendida como uma ciência que investiga o meio natural, possibilitando o conhecimento do nosso planeta e dos processos endógenos e exógenos que nele ocorrem. Desta forma, agimos de modo intencional na criação de diversas atividades antrópicas e na resolução de problemas ambientais inerentes aos modelos que construímos e que designamos de modelos geológicos.

Os cenários e os contextos problemáticos foram cuidadosamente construídos, tendo em conta o currículo da disciplina de Biologia e Geologia, os objetivos e as metas a atingir, bem como o nível etário dos alunos, de modo a fazer emergir a curiosidade e o estímulo para que pudessem formular questões que permitissem abordar os conceitos selecionados. Esses cenários centraram-se num ambiente geográfico próximo dos alunos, ou do seu quotidiano, ou numa situação de um futuro profissional com um papel ou função passível de ser desempenhado pelo aluno, enquanto cidadão. A estratégia privilegiada na nossa intervenção foi a modelação, 
desenvolvida em sala de aula, num contexto de atividade prática que implicou a conceção de modelos tridimensionais e posterior utilização simulando fenómenos ou processos geológicos.

\section{Fundamentação teórica}

Não obstante o contributo de outras metodologias no desenvolvimento cognitivo dos alunos, um questionamento envolvendo questões de nível cognitivo superior e a mobilização de saberes podem ser alcançados com o recurso à Aprendizagem Baseada na Resolução de Problemas (ABRP). Os cenários problematizantes e a procura de soluções envolvidos nesta metodologia promovem uma qualidade das aprendizagens que ressalta da dinâmica colaborativa dos grupos de trabalho e da aprendizagem socialmente construída (FLORES, 2010; INNES, 2006; VASCONCELOS, 2012). A ABRP coloca enfoque especial no envolvimento dos alunos que se encontram inseridos num grupo de trabalho colaborativo, privilegiando-se ações tendentes a aumentar o grau de autonomia dos alunos, que se traduzirão numa independência em relação à orientação fornecida pelo tutor. A ABRP não pode ser fechada e invariável. Apela-se, por isso, ao pluralismo estratégico de atividades e de recursos didáticos, nomeadamente permitindo integrar estratégias com as quais os professores já estão habituados a trabalhar com sucesso (VASCONCELOS; ALMEIDA, 2012) e que são, muitas vezes, referidas em documentos oficiais.

Em Portugal, o Decreto-Lei 7/2001 de 18 de Janeiro (PORTUGAL, 2001) estabelece os princípios orientadores da organização e da gestão curricular dos cursos gerais e dos cursos tecnológicos do Ensino Secundário. O mesmo diploma apresenta o plano de estudo dos cursos gerais constituídos sobre uma matriz curricular que integra uma componente de formação geral e uma componente de formação específica, que, na área das Ciências, compreende a disciplina de Biologia e Geologia no $10^{\circ}$ e no $11^{\circ}$ anos. Apesar da realização de atividades experimentais em geologia não ser, na maioria dos casos, suficiente para a construção de explicações científicas sobre fenómenos físicos, os especialistas em educação defendem que este tipo de atividades deve fazer parte do currículo de ciências, por poder constituir um recurso didático que facilita a compreensão desses fenómenos (LEITE; DOURADO, 2007). Uma das possíveis estratégias, difundida na literatura e, muitas vezes, esquecida no ensino das ciências, é a modelação. Os modelos científicos foram já reconhecidos como tendo um importante papel a desempenhar no processo científico, mas, também, nas práticas de sala de aula (HALLOUN, 2004; JUSTI; GILBERT, 2002, 2003; OH; OH, 2011). No ensino das ciências, em particular da geologia tem havido um incremento da utilização da modelação como estratégia em aulas práticas. Numa primeira fase, os docentes procuraram familiarizar-se com esta estratégia, concebendo modelos, contextualizando-os curricularmente, e testando-os. A conceção dos modelos deve ter em conta a faixa etária dos alunos a que se destina, o fenómeno que se pretende testar ou demonstrar, a sua manipulação e o seu transporte. Contudo, em laboratório, não se consegue reproduzir o fenómeno natural em toda a sua abrangência de espaço e de tempo. Assim, pelas dificuldades em trabalhar o passado geológico, quer devido a problemas de escala temporal e espacial, quer devido à singularidade e à complexidade dos fenómenos e processos geológicos, os geólogos recorrem ao raciocínio por analogia (FRODEMAN, 2001; LAUDAN, 1987). Se o recurso a modelos na investigação proporciona esse tipo de raciocínio, não menos relevante é o seu recurso no ensino da geologia, pois permite clarificar: o conteúdo conceptual, a manipulação 
experimental de variáveis, o desenvolvimento do raciocínio por analogia e a reconstrução dos modelos mentais dos alunos (VASCONCELOS, 2014). Relembremos que a geologia é uma ciência hermenêutica, no sentido de que interpreta dados que não são fornecidos objetivamente, e tem natureza histórica, na medida em que não explica um acontecimento submetendo-o a uma generalização, mas integrando-o num todo organizado (FRODEMAN, 2001). Ao contrário do tradicional método científico, o processo evidenciado nas ciências históricas está menos preocupado com a previsão, centrando-se mais no poder explicativo. Neste pressuposto, o recurso à modelação na sala de aula pretende espelhar o trabalho dos geólogos promovendo o raciocínio histórico, interpretativo e por analogia, que caracteriza essa atividade.

Embora reconhecidas como método de investigação desde o século XIX, foi apenas em 1946, após a publicação, por K. Hubert, de um artigo (em 1939) e de um livro (em 1945), que ficaram estabelecidas as bases de representação escalar da modelação análoga e a definição das condições de similaridade, que se tornaram fundamentais na experimentação em geologia. Contudo, quando construídos utilizando-se materiais com comportamento reológico similar aos materiais geológicos naturais, e, mesmo, esquecendo-se outras condições de representatividade, os modelos são, habitualmente, designados de análogos. A estratégia que suporta a sua utilização intitula-se modelação, consistindo numa atividade laboratorial de simulação de um acontecimento real. No ensino formal da geologia, em atividades práticas, recorre-se a modelos (nem sempre análogos, mas sempre estabelecendo analogias), construídos em escalas muito pequenas, e que se deformam bastante rapidamente, simulando um fenómeno ou um processo real. São simulações que permitem compreender processos geológicos, facilitando a aprendizagem (BOLACHA; DEUS; FONSECA, 2009), embora a atividade deva ser acompanhada da discussão das hipóteses que estão subjacentes à construção do modelo, de modo a permitir a compreensão das suas limitações e impedir a construção de conceções erróneas (BOLACHA, 2014). A manipulação de variáveis num modelo dinâmico permite a correlação entre os diversos fatores, extrapolando a situação da aula para o ambiente natural, favorecendo, assim, a construção de modelos mentais sobre os fenómenos geológicos. Quando devidamente utilizados, permitem a melhoria das práticas e facilitam a consolidação das aprendizagens dos alunos. Contudo, em algumas escolas, os modelos científicos são encarados como réplicas dos acontecimentos reais, gerando conceções alternativas, que são, geralmente, consistentes com uma epistemologia realista naive (TREAGUST; CHITTLEBOROUGH; MAMIALA, 2002).

A utilização de modelos contribui para uma melhor compreensão dos assuntos e constitui uma alavanca para a resolução das questões-problema colocadas em contexto de aula. Os modelos podem ser usados por professores de ciências para demonstrar como algo funciona e para explicar conteúdo conceptual mais complexo (OH; OH, 2011). Para isso, é necessário que seja promovida a transposição didática capaz de potenciar que os conceitos científicos sejam simplificados e reconstruídos, tornando-se mais fácil, para os alunos, a sua compreensão. As transposições didáticas permitem orientar os alunos, por sugestão, para a produção dos seus próprios modelos. Por sua vez, os modelos possibilitam ao professor tirar vantagem das três atividades que a modelação permite: a exploração, a expressão e o questionamento. Este exercício intelectual desenvolvido com os alunos é mais evidenciado quando se empregam metodologias como a ABRP, que permite orientá-los para a conceção dos modelos e para o seu aperfeiçoamento, de modo a favorecer a sua utilização na reprodução, embora parcial, de processos geológicos. 


\section{Metodologia}

Realizou-se um ciclo (produzir, aplicar, avaliar) de uma Investigação \& Desenvolvimento $(I \& D)$, contemplando vários instrumentos de recolha de dados, que permitiram avaliar um programa de intervenção consubstanciado num conjunto de recursos de apoio à investigadora e à sua prática em sala de aula. Todos os instrumentos de investigação e recursos didáticos elaborados foram alvos de um processo de validação, que se constituiu como um meio essencial de aperfeiçoamento, permitindo garantir uma maior qualidade e eficiência no processo. O ciclo da I\&D traduziu-se em materiais e recursos de qualidade, que geraram um impacte positivo nos alunos, sendo estes os primeiros beneficiados pelos produtos elaborados e pelo seu efeito na melhoria dos conhecimentos científicos, no seu desempenho em sala de aula e na melhoria do sucesso escolar.

\section{Instrumentos de recolha de dados}

Foram usados diversos instrumentos envolvidos em técnicas de recolha de dados que permitiram realizar com êxito a investigação. Uma referência às técnicas, instrumentos e elementos envolvidos na investigação está referida no Quadro 1.

Quadro 1. Instrumentos e técnicas de investigação

\begin{tabular}{|c|c|c|c|c|}
\hline Instrumentos & $\begin{array}{c}\text { Técnica de } \\
\text { recolha de dados }\end{array}$ & $\begin{array}{c}\text { Método de análise } \\
\text { de dados }\end{array}$ & Respondente & $\begin{array}{c}\text { Questões de } \\
\text { investigação }\end{array}$ \\
\hline Relatório orientado & Observação & Análise de conteúdo & Investigadora & Q1 e Q2 \\
\hline Relatório orientado & Observação & Análise de conteúdo & $\begin{array}{c}\text { Observadores } \\
\text { externos }\end{array}$ & Q1 e Q2 \\
\hline $\begin{array}{c}\text { Lista de verificação } \\
\text { do envolvimento } \\
\text { dos alunos }\end{array}$ & Observação & $\begin{array}{c}\text { Tratamento estatístico } \\
\text { descritivo }\end{array}$ & Investigadora & Q1 e Q2 \\
\hline $\begin{array}{c}\text { Questionário de } \\
\text { opinião }\end{array}$ & Inquérito & $\begin{array}{c}\text { Tratamento estatístico } \\
\text { descritivo }\end{array}$ & Alunos & Q1 e Q2 \\
\hline V de Gowin & Inquérito & $\begin{array}{c}\text { Análise de conteúdo e } \\
\text { tratamento estatístico } \\
\text { descritivo }\end{array}$ & Alunos & Q2 \\
\hline $\begin{array}{c}\text { Teste de avaliação } \\
\text { de conhecimentos }\end{array}$ & Inquérito & $\begin{array}{c}\text { Análise de conteúdo e } \\
\text { tratamento estatístico } \\
\text { descritivo }\end{array}$ & Alunos & Q \\
\hline
\end{tabular}

Fonte: Ferreira (2012). 
Os relatórios orientados, a lista de verificação do envolvimento dos alunos e o questionário de opinião forneceram dados para dar resposta às seguintes questões de investigação: Q1) Verificar se a modelação é uma estratégia promotora da ABRP e Q2) Verificar se a modelação análoga, como estratégia da $A B R P$, promove o sucesso escolar no ensino da geologia.

Os restantes instrumentos, $\mathrm{V}$ de Gowin e teste de avaliação de conhecimentos, forneceram dados para auxiliar na resposta apenas à segunda questão de investigação: Q2) Será que a modelação análoga, como estratégia da $A B R P$, promove o sucesso escolar no ensino da Geologia?

No seu conjunto, os instrumentos serviram para avaliar a intervenção e encontrar evidências quanto ao papel da modelação integrada na ABRP como promotora do sucesso escolar no ensino da geologia.

\section{Relatório orientado para a professora-investigadora e para os professores observadores}

A professora-investigadora fez uma avaliação do processo, por meio de anotações num relatório orientado que averiguou os seguintes aspetos essenciais: a reação dos alunos ao cenário; como o cenário promoveu o questionamento; a formulação de explicações ou hipóteses para as questões formuladas e a análise das fontes de informação. No mesmo instrumento anotaram-se dados relativos à conceção de modelos pelos alunos, à relação do modelo utilizado com a confirmação das hipóteses levantadas e as respostas científicas às questões, a autonomia manifestada pelos alunos na realização do $\mathrm{V}$ de Gowin e na aplicação de conhecimentos construídos com a modelação.

O relatório orientado para os professores observadores (três professores da disciplina de Biologia e Geologia da escola onde ocorreu a intervenção, que voluntariamente acederam participar) apresentou as mesmas orientações e com a mesma sequência do relatório da professora-investigadora. Pretendeu-se que a avaliação qualitativa realizada por estes professores fosse cruzada com a que foi efetuada pela professora-investigadora, obtendo-se dados porventura relevantes para a investigação.

\section{Lista de verificação do envolvimento dos alunos}

Tendo como base os trabalhos de Hassard e Dias (2009), adaptaram-se aspetos essenciais a registar numa lista de verificação. Os aspetos observados nos alunos basearam-se nos pretendidos numa ABRP promotora de atividades de investigação (questionar, procurar evidências, formular explicações, estabelecer ligações entre a sua explicação e explicações científicas e comunicar resultados). A professora-investigadora, a partir da observação direta, efetuou o seu preenchimento ao longo do programa de intervenção.

\section{Opinião dos alunos acerca da metodologia utilizada}

No final da lecionação de cada bloco de aulas (cada bloco corresponde a uma de três intervenções do programa de intervenção), aplicou-se um questionário de opinião aos alunos. Os alunos foram previamente esclarecidos de que este questionário pretendia avaliar apenas a metodologia implementada, e não os seus saberes científicos. A opinião dos alunos revestiu-se 
de importância significativa para a investigação, sobretudo pelo facto de serem alunos do final do ensino secundário, já detentores de forte espírito crítico e capacidade de argumentação.

\section{V de Gowin}

$\mathrm{O} V$ de Gowin, ferramenta epistemológica que permite compreender sobre o processo de construção do conhecimento, pretendeu avaliar se a aprendizagem dos alunos os ajudaria a descrever os fenómenos naturais, compreendendo as teorias e os modelos atualmente aceites, isto é, se a modelação lhes conferia competências para completarem o preenchimento de um $\mathrm{V}$ de Gowin. Partindo da ideia de que os alunos dominavam conceitos e princípios, admitiu-se que eram, também, capazes de planificar trabalhos práticos e procedimentos experimentais que os conduziam a obter a resposta a uma questão-problema inicial. Como se verificará, tal facto traduziu-se em alunos capazes de refletirem e discutirem propostas de elaboração de modelos.

\section{Teste de avaliação de conhecimentos}

Foram realizados testes individuais que foram inseridos na avaliação sumativa dos alunos, tendo sido concebidos e elaborados de acordo com o desenho apresentado pelos testes do Ministério da Educação. Procurou-se que fossem constituídos pelo mesmo número de grupos, com a mesma tipologia de questões, a mesma cotação e critérios de classificação similares aos que se aplicam nos exames nacionais. Os resultados da avaliação sumativa revestiram-se de grande importância por permitirem avaliar a qualidade das aprendizagens, quando os alunos foram sujeitos a uma metodologia de ensino diferente relativamente às restantes aulas. Impôsse que a avaliação sumativa exprimisse uma interpretação, o mais rigorosa possível, dos dados recolhidos durante os processos de ensino e de aprendizagem.

\section{O programa de intervenção}

O programa de intervenção (PI) foi realizado na componente de geologia da disciplina de Biologia e Geologia durante 13 aulas, algumas com a duração de noventa minutos e outras de 135 minutos (total de mil, quatrocentos e quarenta minutos). Os participantes na intervenção foram vinte e dois alunos de $11^{\circ}$ ano a frequentar a disciplina de Biologia e Geologia (amplitude de idades dos sete aos 15 aos anos).

O PI, como já referido, apoiou-se numa metodologia de ensino baseada em problemas e apoiada em modelos geológicos. Assim, no desenvolvimento da atividade, tivemos sempre presente a obrigatoriedade de distinguir, muito claramente, as analogias entre o modelo e o processo geológico que se queria investigar, determinando que variável geológica real representava cada uma das variáveis utilizadas no modelo, e que fenómenos ou processos reais estavam a ser simulados (ALVAREZ; GARCÍA DE LA TORRE, 1996).

$\mathrm{Na}$ exploração dos resultados da modelação esteve, também, sempre presente a necessidade de espelhar a atividade de investigação do geólogo, isto é, promover a interpretação dos resultados numa perspetiva interpretativa, análoga e histórica. Assim, a causa e o efeito potenciados pela modelação eram sempre transpostos para situações reais (análogos naturais), cujas causas, não podendo ser analisadas no presente, foram interpretadas com o auxílio desse 
processo laboratorial de reconstituição e simulação de um efeito no presente. Como refere Bolacha (2014, p. 42), em geologia:

Através do princípio do atualismo, estabelecem-se relações de semelhança entre efeitos geológicos, à partida diferentes, porque separados no tempo. Enquanto as relações causa-efeito dos fenómenos atuais podem ser comprovadas por observação direta, as dos fenómenos passados não podem, deste modo, ser comprovadas. Só podem ser inferidas através da aplicação do princípio do atualismo, pressupondo que as causas presentes e passadas terão sido as mesmas.

A modelação é certamente a estratégia didática que mais fielmente promove este tipo de interpretação e analogia em sala de aula.

Para a operacionalização do estudo, foram selecionados três conteúdos programáticos integrados na disciplina escolhida para se realizar a intervenção: (i) Bacias hidrográficas e zonas de vertente; (ii) Deformação das rochas; e (3) Águas subterrâneas. Para cada um dos conteúdos programáticos em que incidiu a investigação, estabeleceu-se que a implementação das diferentes estratégias decorreria numa sequência determinada. Por ordem cronológica, ocorreram: (i) fase de apresentação do cenário problemático; (ii) fase de questionamento, ocorrência de pequenas investigações orientadas; (iii) fase de conceção de modelos para a realização de atividades práticas de simulação (neste caso, experimentais) que permitissem recolher dados e validar as hipóteses; (iv) fase de realização da atividade experimental com recurso aos modelos (um modelo para cada cenário); (v) fase de avaliação sumativa dos alunos, com preenchimento de V de Gowin por cada atividade experimental e teste de avaliação de conhecimentos (FERREIRA, 2012).

Uma breve apresentação de cada fase é feita de seguida:

\section{(i) Fase de apresentação do cenário}

Para cada conteúdo, desenhou-se um problema motivador que constituiu o cenário (num total de três cenários, um para cada intervenção do PI), estimulou os alunos e envolveu-os na investigação. Os cenários centraram-se num ambiente geográfico próximo dos alunos, ou numa área geográfica de interesse nacional e/ou regional, em termos paisagísticos, ambientais e sociais. Os cenários foram o ponto de partida para os alunos formularem questões, que estimulassem a procura de solução suscetível de dar início à investigação.

Para a implementação do PI, os alunos foram distribuídos em grupos heterogéneos de cinco ou seis elementos, de modo a maximizarem o trabalho colaborativo e a partilharem aprendizagens à medida que iam concretizando as tarefas solicitadas.

\section{(ii) Fase de questionamento}

Após a leitura e compreensão do problema, os alunos trabalharam colaborativamente para elaboraram questões. Esta fase revelou-se de importância extrema, uma vez que as questões formuladas constituíram o ponto de partida para as atividades subsequentes. A análise das principais questões permitiu a sua distribuição por nível cognitivo e por subcategorias, de acordo com a taxonomia apresentada por Dalghren e Öberg (2001) já mencionada em trabalhos de autores portugueses como, por exemplo: Carvalho e Dourado (2009), Ferreira, Alencoão e Vasconcelos (2011) e Palma e Leite (2006). 
Verificou-se que as questões formuladas, para qualquer um dos cenários, foram maioritariamente de nível cognitivo superior: Que relação existe entre a intensidade de precipitação, a escorrência superficial e a formação de cheias rápidas? Que caraterísticas apresenta o material rochoso que favoreça a formação de falhas? ou Como se explica a variação sazonal da zona de aeração?

De acordo com Palma e Leite (2006), quando se utiliza a ABRP, as questões formuladas pelos alunos devem ser de nível elevado, traduzindo-se a sua resposta numa compreensão de conceitos. As questões de nível cognitivo e de subcategoria mais simples, como as de conhecimento, tornam-se pouco úteis, sobretudo quando se trata de alunos do ensino secundário. Foram apresentadas, ainda, questões relacionadas com a procura de soluções: Como sepode praticar o desenvolvimento sustentado, tendo em conta as características da paisagem duriense e as alterações climáticas, sem por em risco bens materiais e humanos?; Como se pode explicar, experimentalmente, a formação do maciço tectónico da serra da estrela? Ou Como se pode explicar, experimentalmente, a formação de uma depressão tectónica ou de um graben?

\section{(iii) Fase de conceção do modelo}

Após elaboração de várias questões, os alunos geraram explicações que foram discutidas no grupo turma. Para cada cenário, foi selecionada, pelo grupo turma, a explicação que constituiu a hipótese de investigação. Seguidamente, solicitou-se, a cada grupo, a conceção de um modelo que permitisse realizar uma simulação experimental para procurarem possíveis soluções. Cada grupo procedeu à conceção de um modelo experimental. Em discussão aberta e organizada, os alunos comentaram os diferentes modelos, apontando os aspetos positivos e os erros que continham, até obterem um modelo de consenso que permitiu a realização de uma atividade de simulação experimental.

\section{(iv) Atividade experimental}

Para cada modelo consensualmente aceite, os alunos elaboraram um procedimento experimental que serviu de base ao desenvolvimento da correspondente atividade experimental. Os dados recolhidos pelos alunos e as conclusões a que chegaram, foram utilizados para responder a questões colocadas na fase de questionamento.

\section{(v) Avaliação dos alunos}

A avaliação sumativa dos alunos realizou-se com a utilização do V de Gowin (realizado após cada uma das atividades experimentais) e pelo teste de avaliação de conhecimentos (aplicado duas semanas após aplicação do PI).

\section{Análise de resultados}

Para a avaliação do produto, tal como foi mencionado na secção dos instrumentos de recolha de dados, recorreu-se a: (i) relatórios orientados (para a professora investigadora e professores observadores); (ii) lista de verificação do envolvimento dos alunos. Estes instrumentos foram dirigidos para uma avaliação contínua e formativa dos alunos, nomeadamente em termos de desenvolvimento de competências conceptuais, procedimentais e atitudinais. Para a análise do processo, utilizaram-se: os conteúdos dos relatórios orientados para a professora-investiga- 
dora e para os professores observadores, a lista de verificação do envolvimento dos alunos, e a opinião dos alunos relativamente à metodologia utilizada (FERREIRA, 2012).

Para uma melhor compreensão dos resultados apresenta-se uma análise conjunta comparativa dos dados obtidos em cada uma das intervenções do PI (relembramos que cada intervenção, num total de três, implicou um cenário e uma investigação independente com um modelo específico).

\section{Relatório da professora-investigadora e dos professores observadores}

Estes relatórios foram preenchidos pela professora-investigadora no final de cada conteúdo lecionado, recorrendo a todos os dados/observações recolhidos durante as aulas. As professoras observadoras entregaram os relatórios no final de cada conjunto de aulas observadas. Da sua análise, verificou-se que o recurso à modelação análoga implementada pela professora -investigadora foi bem aceite pelos alunos, e as professoras observadoras reconheceram-lhe um efeito benéfico na motivação e envolvimento dos alunos. A análise dos registos da professora-investigadora, analisados em conjunto com os que foram realizados pelas professoras observadoras, indicou que, ao longo das três intervenções, ocorreu nos alunos: (i) gradual envolvimento na formulação de questões científicas partindo de casos que se relacionavam com problemas, mais ou menos, próximos do seu quotidiano em termos emocionais e/ou geográficos; (ii) crescente formulação de explicações e elaboração de hipóteses para as questões que tinham formulado; (iii) incremento na procura de explicações para as questões-problema e hipóteses colocadas após leitura e interpretação dos dados contidos nas fontes de informação; (iv) acréscimo da recolha de evidências a partir dos documentos fornecidos pela professora-investigadora. Pelo exposto, este instrumento indicou que a estratégia da modelação análoga traduziu-se em benefícios na aprendizagem dos alunos, e potenciou a melhoria dos seus resultados ao nível do domínio escrito e oral da língua portuguesa.

No seu relatório, a professora-investigadora menciona

Os alunos foram muito empenhados na conceşão de um modelo análogo, na sua apresentação e discussão. [...] Foi bem evidente que a discussão gerada no seio dos grupos e na turma permitiu a reformulação dos modelos apresentados, revelando a sua capacidade criativa, a crítica construtiva e a colaboração entre os diferentes grupos de trabalho. Salientou-se ainda, a capacidade de idealizarem um procedimento experimental, quais as variáveis que pretendiam utilizar e os resultados que esperavam obter. Reconhece-se que os alunos necessitaram de tempo para discutir e reformular os modelos concebidos, [...] foram muito rigorosos relativamente ao procedimento experimental dando importância à montagem que teria que servir de controlo. [...] Os dados recolhidos com as atividades experimentais, recorrendo ao modelo análogo, permitiram aos alunos recolher evidências e relacioná-las com as hipóteses e a construção de respostas para as questões cientificas.

As professoras observadoras referiram que: 
Os alunos trocaram ideias entre eles e com a professora sobre a forma como poderiam construir um modelo análogo que pudesse relacionar as causas com os seus efeitos. [Observadora 2]

Quando o apresentaram à turma sujeitando-o a uma discussão crítica entendeu-se que tinham compreendido o que a professora solicitou, uma vez que quando alguma situação era menos entendida a professora colocava questões acerca da possivel utilização e viabilidade do modelo. [Observadora 1]

As atividades experimentais realizadas forneceram evidências que relacionavam causas com os efeitos que produziam, e os alunos demonstraram ter compreendido isso. [Observadora 1]

Demonstraram autonomia na conceção de um aparato experimental e na elaboração de procedimentos, com o risco de se sujeitarem a inúmeras dúvidas e críticas, embora construtivas, da parte de colegas e de terem que esclarecê-los. [Observadora 3]

\section{Lista de verificação do envolvimento dos alunos}

A lista de verificação era preenchida ao longo de cada intervenção. A título de exemplo, apresenta-se a lista de verificação preenchida para um dos grupos de trabalho (Quadro 2), evidenciando-se a classificação em cada uma das intervenções (1)PI1 - primeira intervenção, (2)PI2 - segunda intervenção, e(3)PI3 - terceira intervenção).

A análise conjunta do envolvimento dos alunos da turma permitiu averiguar que, durante a primeira intervenção, foram evidenciadas menos capacidades: de formular questões cientificamente orientadas, de identificar evidências para elaborar respostas, e de enunciar explicações para as evidências. Ao longo da segunda intervenção, o grau de envolvimento dos

Quadro 2. Lista de verificação do envolvimento dos alunos ao longo das intervenções

\begin{tabular}{|l|c|c|c|c|c|}
\hline & $\begin{array}{c}\text { Envolvido } \\
\text { em questões } \\
\text { cientificamente } \\
\text { orientadas }\end{array}$ & $\begin{array}{c}\text { Dá prioridade } \\
\text { a evidências } \\
\text { na sua } \\
\text { resposta }\end{array}$ & $\begin{array}{c}\text { Formula } \\
\text { explicações } \\
\text { para as } \\
\text { evidências }\end{array}$ & $\begin{array}{c}\text { Estabelece ligações } \\
\text { entre a sua explicação } \\
\text { e explicações } \\
\text { científicas }\end{array}$ & $\begin{array}{c}\text { Comunica } \\
\text { e justifica } \\
\text { explicações }\end{array}$ \\
\hline Aluno A & (1) (2) (3) & (1) (2) (3) & (2) (3) & (2) (3) & (2) (3) \\
\hline Aluno B & (1) (2) (3) & (1) (2) (3) & (2) (3) & (3) & (3) \\
\hline Aluno C & (1) (2) (3) & (1) (2) (3) & (1) (2) (3) & (1) (2) (3) & (3) \\
\hline Aluno D & (1) (2) (3) & (1) (2) (3) & (1) (2) (3) & (1) (2) (3) & (3) \\
\hline Aluno E & (2) (3) & (1) (2) (3) & (2) (3) & (3) & \\
\hline
\end{tabular}

Legenda: (1)primeira intervenção; (2) segunda intervenção; (3)terceira intervenção.

Fonte: Ferreira (2012). 
alunos melhorou, tornando-se bastante satisfatório. Ao longo da terceira intervenção, aumentou o número de alunos com capacidades de estabelecer ligações entre as suas explicações e as explicações científicas, e de comunicar e justificar explicações.

\section{Opinião dos alunos acerca da metodologia utilizada}

Tendo como base os resultados aos questionários aplicados no final de cada uma das três intervenções, elaboraram-se tabelas que permitiram analisar os resultados.

Relativamente à metodologia utilizada pela professora-investigadora (ver tabelas 1, 2 e 3), concluiu-se que, progressivamente, da primeira para a terceira intervenção, os alunos reconheceram virtualidades neste tipo de metodologia, com benefícios na aprendizagem.

Tabela 1. Opinião dos alunos em relação à apresentação do problema e ao questionamento nas intervenções

\begin{tabular}{lrrr}
\hline & \multicolumn{3}{c}{$\mathbf{N}^{\text {o }}$ de alunos } \\
\cline { 2 - 4 } \multicolumn{1}{c}{ Afirmações } & PI1 & PI2 & PI3 \\
\hline Coloquei questões. & 6 & 12 & 14 \\
Selecionei questões dentro das que foram apresentadas e coloquei novas questões. & 7 & 6 & 6 \\
Envolvi-me nas questões fornecidas pela professora e pelos documentos materiais. & 9 & 4 & 2
\end{tabular}

Legenda: PI1 primeira intervenção; PI2 segunda intervenção; PI3 terceira intervenção.

Fonte: Ferreira (2012).

Os alunos, com a evolução do programa de intervenção, foram aumentando o número de questões e o seu grau de envolvimento na metodologia.

Tabela 2. Opinião dos alunos relativamente às evidências que encontraram nos documentos e na modelação nas aulas das intervenções

\begin{tabular}{lrrr}
\hline \multirow{1}{c}{ Afirmações } & \multicolumn{3}{c}{$\mathbf{N}^{\mathbf{0}}$ de alunos } \\
\cline { 2 - 5 } & PI1 & PI2 & PI3 \\
\hline $\begin{array}{l}\text { Sabia o que era uma evidência e recolhi-a nos documentos fornecidos. } \\
\text { Apenas procurei as evidências nos documentos fornecidos, após a professora me } \\
\text { explicar o que era uma evidência. }\end{array}$ & 10 & 12 & 14 \\
A professora deu-me as evidências e a informação sobre como se analisam. & 2 & 7 & 1 \\
\hline
\end{tabular}

Legenda: PI1 primeira intervenção; PI2 segunda intervenção; PI3 terceira intervenção.

Fonte: Ferreira (2012).

Os alunos, com a evolução do programa de intervenção, aprenderam a recolher autonomamente as evidências.

A análise conjunta da opinião dos alunos acerca da metodologia, e expressa nas tabelas 3, 4 e 5, indica que os alunos consideraram que esta: (i) foi facilitadora da aprendizagem; (ii) permitiu aprender conteúdos científicos; (iii) ajudou a formular explicações para fenómenos e processos geológicos; (iv) facilitou a compreensão de relações causa-efeito na natureza.

Os alunos, com a evolução do programa de intervenção, foram aprendendo a, autonomamente, confrontarem hipóteses com explicações científicas. 
Tabela 3. Opinião dos alunos relativamente às análises entre as hipóteses e as explicações após a utilização da modelação análoga nas aulas das intervenções

\begin{tabular}{lccc}
\hline \multicolumn{1}{c}{ Afirmações } & \multicolumn{2}{c}{$\mathbf{N}^{\mathbf{o}}$ de alunos } \\
\cline { 2 - 4 } & PI1 & PI2 & PI3 \\
\hline $\begin{array}{l}\text { Autonomamente, examinei os resultados e os documentos fornecidos e estabeleci } \\
\text { ligações entre as minhas hipóteses e as explicações científicas encontradas. }\end{array}$ & 8 & 10 & 12 \\
$\begin{array}{l}\text { Fui guiado pela professora para confrontar as minhas hipóteses com as } \\
\text { explicações científicas. }\end{array}$ & 12 & 10 & 9 \\
$\begin{array}{l}\text { A professora explicou-me como confrontava as minhas hipóteses com as } \\
\text { explicações científicas. }\end{array}$ & 2 & 2 & 1 \\
\hline
\end{tabular}

Legenda: PI1 primeira intervenção; PI2 segunda intervenção; PI3 terceira intervenção.

Fonte: Ferreira (2012).

\section{V de Gowin}

$\mathrm{Na}$ investigação realizada, os alunos preencheram seis $\mathrm{V}$ de Gowin. No decorrer da intervenção 1 (PI1), foram realizadas três atividades experimentais para responder às questões -problema: De que forma o revestimento vegetal interfere nos movimentos em massa? Como se poderia testar a ação da intensidade da precipitação no volume de água escoado superficialmente?, e Qual a influência do declive em solos desprovidos de vegetação, na escorrência superficial e no transporte de sedimentos?, que permitiram o preenchimento de três V de Gowin. Em PI2, foram realizadas duas atividades experimentais para responder às questões-problema: Como se pode explicar a formação do maciço tectónico da serra da estrela?, e Como se pode explicar a formação da bacia de Telões?, permitindo a realização de dois V de Gowin. Durante a intervenção 3 (PI3), para responder à questão-problema Por que motivo pode acontecer que um poço seque?, foi realizada uma atividade experimental e o respetivo V de Gowin.

A avaliação escrita dos alunos após a realização das atividades experimentais (Tabela 4) permitiu a realização de comparações que traduziram a progressão da capacidade dos alunos para convencionar a construção do seu conhecimento.

Tabela 4. Classes de distribuição das menções qualitativas relativas aos resultados dos $\mathrm{V}$ de Gowin (VG1, VG2, VG3, VG4, VG5 e VG6)

\begin{tabular}{|c|c|c|c|c|c|}
\hline Relatório Classes & 0 orł50 & $50 \vdash 100$ & $100-150$ & $150-175$ & 175 ト-200 \\
\hline Menção & Fraco & Insuficiente & Suficiente & Bom & Muito bom \\
\hline VG1 & 0 & 3 & 11 & 4 & 4 \\
\hline VG2 & 0 & 2 & 10 & 6 & 4 \\
\hline VG3 & 0 & 0 & 10 & 8 & 4 \\
\hline VG4 & 0 & 0 & 9 & 11 & 2 \\
\hline VG5 & 0 & 0 & 7 & 11 & 4 \\
\hline VG6 & 0 & 0 & 3 & 10 & 6 \\
\hline
\end{tabular}

Fonte: Ferreira (2012). 
Verificou-se que a menção de satisfaz apresentou maior frequência para os três primeiros relatórios (VG1, VG2 e VG3). A menção de bom exibiu maior frequência para os três últimos relatórios (VG3, VG4 e VG5). Quando se somou a frequência das menções de bom e muito bom, verificou-se que aumentou sempre desde VG1 até VG6, traduzindo uma crescente apropriação de saberes por parte dos alunos. Ao realizar-se a distribuição das classificações finais de cada relatório por classes, de acordo com a regra de Sturges (Tabela 5), constatou-se que a classe $50-75$, correspondente a uma classificação mais baixa, contém apenas um aluno.

A classe 75 - 100, que traduz, também, uma classificação negativa, apresentou uma frequência de dois para VG1 e VG2. Chamaram a atenção as classes $150 \vdash 175$ e $175 \vdash \dashv 200$, com uma tendência crescente de VG1 até VG6, demonstrando um melhor desempenho e investimento por parte dos alunos. O relatório VG6 foi realizado tendo como base um modelo que foi considerado o mais difícil de conceber pelos alunos, tal como o procedimento que serviu de base à atividade experimental. $\mathrm{O}$ empenhamento dos alunos na recolha de evidências e de dados levou a que a atividade experimental fosse repetida, por solicitação dos mesmos.

Tabela 5. Classes de distribuição das classificações finais nos V de Gowin

\begin{tabular}{|c|c|c|c|c|c|c|c|c|}
\hline $\begin{array}{l}\text { Classes } \\
\text { Relatório }\end{array}$ & 0 -ト 25 & 25 - 50 & $50 \vdash 75$ & $75 \vdash 100$ & $100-125$ & $125 \vdash 150$ & $150 \vdash 175$ & $175 \biguplus 200$ \\
\hline VG1 & 0 & 0 & 1 & 2 & 4 & 7 & 4 & 4 \\
\hline VG2 & 0 & 0 & 0 & 2 & 2 & 8 & 6 & 4 \\
\hline VG3 & 0 & 0 & 0 & 0 & 1 & 9 & 8 & 4 \\
\hline VG4 & 0 & 0 & 0 & 0 & 1 & 8 & 11 & 2 \\
\hline VG5 & 0 & 0 & 0 & 0 & 0 & 7 & 11 & 4 \\
\hline VG6 & 0 & 0 & 0 & 0 & 0 & 3 & 10 & 9 \\
\hline
\end{tabular}

Fonte: Ferreira (2012).

Verificou-se que os alunos necessitaram de observar mais do que uma vez o desenrolar da atividade experimental, para melhorarem a sua compreensão acerca das relações causa-efeito, o que se traduziu em melhores resultados nas classificações finais do relatório.

\section{Testes de avaliação de conhecimentos}

A aplicação dos testes de avaliação de conhecimentos foi realizada de acordo com o que estava planificado. Assim, o teste 1 (T1) corresponde à avaliação de conhecimentos resultantes da primeira intervenção; o teste 2 (TI2) corresponde à avaliação de conhecimentos resultantes da segunda intervenção, e o teste 3 (TI3) corresponde à avaliação de conhecimentos resultantes da terceira intervenção. A Tabela 6 apresenta as classes que determinaram a obtenção das menções qualitativas.

Verificou-se que a aplicação de conhecimentos nos testes sofreu uma melhoria significativa, traduzindo um empenho, uma autonomia e um envolvimento dos alunos que culminaram com um domínio mais significativo dos conteúdos de aprendizagem. A melhoria dos seus 
resultados escolares ocorreu como consequência da apropriação de conhecimentos associada à estratégia e metodologia utilizadas. Assim, os resultados obtidos, pelos alunos, nos testes de conhecimentos configuram a existência de uma concordância entre a opinião da professora -investigadora e dos observadores com a opinião dos alunos. São, ainda, concordantes com uma resposta afirmativa às questões-problema que lhe estão subjacentes na investigação que foi levada a cabo.

Tabela 6. Classes de distribuição das menções qualitativas obtidas nos testes

\begin{tabular}{|c|c|c|c|c|c|}
\hline Relatório Classes & $0 \vdash-50$ & $50-100$ & $100-150$ & $150 \vdash 175$ & $175 \vdash \dashv 200$ \\
\hline Menção & Fraco & Insuficiente & Suficiente & Bom & Muito bom \\
\hline T1 & 2 & 1 & 8 & 6 & 5 \\
\hline T2 & 0 & 1 & 8 & 7 & 6 \\
\hline T3 & 0 & 0 & 5 & 7 & 10 \\
\hline
\end{tabular}

Fonte: Ferreira (2012).

\section{Conclusões}

A análise qualitativa dos dados revela que a modelação pode e deve ser utilizada no ensino da geologia. Relembramos que foram asseguradas as devidas diferenças entre o modelo e a natureza, garantindo a compreensão dos processos e fenómenos numa relação causa e efeito, procurando evitar-se, assim, a criação de conceções alternativas, tal como sugerido por outros autores (ALENCOÃO et al., 2012). O estudo permitiu concluir que as atividades experimentais, tão do agrado dos alunos, mobilizaram-nos na conceção de modelos e na idealização de procedimentos experimentais compatíveis com o aparato experimental e com o que pretendiam testar. As evidências recolhidas nas atividades de simulação experimentais, e os dados que estas permitiram recolher, constituíram auxiliares para a procura de soluções a questões-problema. Os dados utilizados no preenchimento do V de Gowin, nomeadamente nos itens de registo de resultados e conclusões, constituíram meios de avaliar a capacidade de argumentação dos alunos e de aplicação, demonstrando a existência de aprendizagens significativas. Assim, demonstrase que a modelação é uma estratégia com imensas potencialidades educativas entre alunos da faixa etária considerada, permitindo diferentes graus de exigência, facilitando a conjugação de diferentes fatores e de manipulação de variáveis. Ao nível dos alunos, concluiu-se que estes compreenderam que a simulação de fenómenos e processos naturais, em escalas espaciotemporais compatíveis com o espaço e o tempo de aula, era exequível. Finalmente, referimos que a modelação, integrada numa abordagem investigativa (ABRP), auxiliou os alunos: no desenvolvimento de processos científicos, na construção e aplicação de capacidades investigativas, e num domínio de saberes capaz de possibilitar a sua mobilização na resolução de problemas. 
Ferreira, C.; Alencoão A ; Vasconcelos, C.

\section{Referências}

ALENCOÃO, A. et al. Fluxo subterrâneo e dinâmico de aquíferos em meios porosos: utilização de modelos análogos. Geonovas, Lisboa, n. 25, p. 35-40, 2012.

ALVAREZ, R. M.; GARCÍA DE LA TORRE, E. G. Los modelos analógicos en geología: implicaciones didácticas. Ejemplos relacionados con el origen de materiales terrestres.

Enseñanza de las Ciencias de la Tierra, Girona, v. 4, n. 2, p. 133-139, 1996. Disponível em: <http://www.raco.cat/index.php/ECT/article/view/88230/123957>. Acesso em: 03 out. 2014.

BOLACHA, E. Modelos de dinâmica da terra aplicados à geologia de Portugal: relevância da experimentação análoga no ensino e na divulgação da geologia. 2014. 648 f. Tese (Doutoramento em Geologia) - Universidade de Lisboa, Lisboa, 2014.

BOLACHA, E.; DEUS, H. M.; FONSECA, P. E. Modelação análoga em geologia, na sala de aula. In: CURSO DE ACTUALIZAÇÃO DE PROFESSORES EM GEOCIÊNCIAS, 29., 2009, Lisboa. Atas... Lisboa: Escola Superior de Educação de Lisboa, 2009. p. 83-85.

CARVALHO, C. J.; DOURADO, J. A formulação de questões a partir de cenários problemáticos: um estudo com alunos de ciências naturais do $3^{\circ}$ ciclo do ensino básico português. In: CONGRESSO INTERNACIONAL GALEGO-PORTUGUÊS DE PSICOPEDAGOGIA, 10., 2009, Braga. Atas... Braga: Universidade do Minho, 2009. p. 2615-2628.

DALGHREN, M.; ÖBERG, G. Questioning to learn and learning to question: structure and function of problem-based learning scenarios in environmental science education. Higher Education, Dordrecht, v. 41, n. 3, p. 263-282, 2001.

FERREIRA, C. D. A. A modelação análoga no ensino da geologia: um estudo centrado na aprendizagem baseada na resolução de problemas. 2012. 353 f. Tese (Doutoramento em Ciências da Terra e da Vida) - Universidade de Trás-os-Montes e Alto Douro, Vila Real, 2012.

FERREIRA, C.; ALENCOÃO, A.; VASCONCELOS, C. Preservação da biodiversidade em áreas degradadas: uma intervenção centrada na aprendizagem baseada na resolução de problemas. In: ENCONTRO NACIONAL DE EDUCAÇÃO EM CIÊNCIAS, 14., 2011, Braga. Atas... Braga: Universidade do Minho, 2011. 01 CD-ROM.

FLORES, J. El aprendizaje basado en problemas y la V de Gowin en el aprendizaje profundo. In: INTERNATIONAL CONFERENCE OF PAN-AMERICAN NETWORK OF PROBLEM-BASED LEARNING, 2010, São Paulo. Anais... S. Paulo: Universidade de São Paulo, 2010. Disponível em: <http://www.uspleste.usp.br/pbl2010/trabs/trabalhos/ TC0018-2.pdf >. Acesso em: 03 out. 2014.

FRODEMAN, R. A. Epistemologia das geociências. In: MARQUES, L.; PRAIA, J. (Ed.). Geociências nos currículos dos ensinos básico e secundário. Aveiro: Universidade de Aveiro, 2001. p. 39-57. 
O recurso à modelação no ensino das ciências: ...

HALLOUN, I. A. Modeling theory in science education. Dordrecht: Kluwer, 2004.

HASSARD, J.; DIAS, M. The art of teaching science: inquiry and innovation in middle school and high school. New York: Routledge, 2009.

INNES, R. What can learning science contribute to our understanding of the effectiveness of problem-based learning groups? Journal of Management Education, Thousand Oaks, v. 30, n. 6, p. 751-764, 2006.

JUSTI, R. S.; GILBERT, J. K. Modelling, teachers' views on the nature of modelling, and implications for the education of modellers. International Journal of Science Education, Abingdon, v. 24, n. 4, p. 369-387, 2002.

Teachers' views on the nature of models. International Journal of Science Education, Abingdon, v. 25, n. 11, p. 1369-1386, 2003.

LAUDAN, R. From mineralogy to geology: the foundations of a science, 1650-1830. Chicago: The University of Chicago Press, 1987.

LEITE, L.; DOURADO, L. G. P. Das reformas curriculares às práticas em sala de aula: o caso das actividades laboratoriais no ensino das ciências. Boletim Paulista de Geografia, São Paulo, v. 86, p. 95-122, 2007.

LEITE, L.; ESTEVES, E. Resolução de problemas: um estudo com futuros professores de física e química. In: INTERNATIONAL CONFERENCE OF PAN-AMERICAN NETWORK OF PROBLEM-BASED LEARNING, 2006, Lima. Actas... Lima: Pontificia Universidad Católica del Peru, 2006. 01 CD-ROM.

OH, P. S.; OH, S. J. What teachers of science need to know about models: an overview. International Journal of Science Education, Abingdon, v. 33, n. 8, p. 1109-1130, 2011.

OSBORNE, J.; DILLON, J. Science education in Europe: critical reflections. London: The King's College: Nuffield Foundation, 2008.

PALMA, C.; LEITE, L. Formulação de questões, educação em ciências e aprendizagem baseada na resolução de problemas: um estudo com alunos portugueses do $8^{\circ}$ ano de escolaridade. In: INTERNATIONAL CONFERENCE OF PAN-AMERICAN NETWORK OF PROBLEM-BASED LEARNING, 2006, Lima. Actas... Lima: Pontificia Universidad Católica del Peru, 2006. 01 CD-ROM.

PORTUGAL. Decreto-lei n. 7/2001 de 18 de janeiro. Diário da República, Lisboa, 18 jan. 2014. Série A, p. 265. Disponível em: <http://legislacao.min-edu.pt/np4/ np3content/?newsId=4379\&fileName=decreto_lei_7_2001.pdf > . Acesso em: 03 out. 2014.

SJØBERG, S.; SCHREINER, C. How do learners in different cultures relate to science and technology? Results and perspectives from the project ROSE. Asia-Pacific Forum on Science Learning and Teaching, Hong Kong, v. 6, n. 2, p. 1-16, 2005.

TREAGUST, D. F.; CHITTLEBOROUGH, G.; MAMIALA, T. L. Students' understanding of the role of scientific models in learning science. International Journal of Science Education, Abingdon, v. 24, n. 4, p. 357-368, 2002. 
Ferreira, C.; Alencoão A ; Vasconcelos, C.

VASCONCELOS, C. Teaching environmental education through PBL: evaluation of a teaching intervention program. Research in Science Education, Dordrecht, v. 42, n. 2, p. 219-232, 2012.

. O papel dos modelos e a estratégia da modelação no ensino da geologia: novas questões para a investigação educacional. In: ENCONTRO NACIONAL DE EDUCAÇÃO EM CIÊNCIAS, 15., 2014, Faro. Livro de resumos... Faro: Universidade do Algarve, 2014. p. 51.

VASCONCELOS, C.; ALMEIDA, A. Aprendizagem baseada na resolução de

problemas no ensino das ciências: propostas de trabalho para ciências naturais, biologia e geologia. Porto: Porto Editora, 2012.

Artigo recebido em 05/04/13. Aceito em 16/04/14. 